SISTEMA
ELETRONIICO
DE REVISTAS
SER I UfPR

\title{
Análise bibliométrica das publicações em quatro eventos científicos sobre gestão de resíduos sólidos urbanos a partir da Política Nacional de resíduos Sólidos - Lei no 12.305/2010
}

\section{Bibliometric analysis of publication in four scientific events on the management of solid urban waste from the National Solid Waste Policy - Law no 12.305/2010}

\author{
Estela Cristina BONJARDIM ${ }^{1}$, Raquel da Silva PEREIRA ${ }^{1 *}$, Eliana Vileide GUARDABASSIO ${ }^{1}$ \\ ${ }^{1}$ Programa de Pós-graduação em Administração, Universidade Municipal de São Caetano do Sul (USCS), São Caetano do Sul, SP, Brasil. \\ *E-mail de contato: raquel.pereira@prof.uscs.edu.br
}

Artigo recebido em 5 de julho de 2017, versão final aceita em 11 de maio de 2018.

\begin{abstract}
RESUMO: $\quad$ Este artigo descreve os resultados de uma pesquisa na literatura científica relacionada à Gestão de Resíduos Sólidos Urbanos, publicada nos anais de quatro conferências brasileiras relevantes na área de Administração de Empresas: Encontro da ANPAD (ENANPAD), Encontro Internacional sobre Gestão e Meio Ambiente (ENGEMA), Seminários em Administração (SEMEAD) e Simpósio de Administração, Logística e Operações Internacionais (SIMPOI). A coleta de dados considerou o período de 2011 a 2016, que reflete o ajuste de conduta para atender aos requisitos da Lei $n^{\circ} 12.305 / 2010$, conforme proposto pela Política Nacional de Resíduos Sólidos. A pesquisa foi realizada por meio de um estudo empírico-analítico, com aplicação de técnicas bibliométricas que identificaram, nos anais dos eventos, 447 artigos referentes à Gestão Ambiental e aos resíduos sólidos produzidos nos municípios. Destes, 331 (73,5\%) referiram-se especificamente ao gerenciamento de resíduos sólidos e foram utilizados como amostra documental para o presente artigo. Como resultado da análise do presente trabalho, foram identificados 45 elementos abordados na gestão de resíduos sólidos urbanos. Esses elementos foram classificados em quatro categorias de análise: Cooperativas de catadores, Lógica reversa, Política Nacional de Resíduos Sólidos e Desperdício. Dentre as conclusões que chegamos com as análises do conteúdo, podemos listar: aumento gradativo da discussão sobre Gestão de Resíduos Sólidos Urbanos no Brasil, desde que a Lei foi editada e implementada, o que aponta uma tendência do tema tornar-se mais explorado no âmbito nacional da produção acadêmica, considerando sua importância no debate ambiental internacional; observação do ENGEMA enquanto evento que concentra o maior percentual de Gestão de Resíduos Sólidos Urbanos, atingindo 65,86\% dos artigos publicados na temática; constatação de que, em termos de afiliação do autor, há predominância de pesquisadores de universidades
\end{abstract}


federais localizadas nas regiões Sul e Nordeste do Brasil; evidenciação, por meio dos artigos, da existência de práticas bem-sucedidas de reciclagem, logística reversa e coleta seletiva.

Palavras-chave: gestão ambiental; resíduos sólidos urbanos; bibliometria; lei nº 12.305/2010.

ABSTRACT: This paper describes the results of a research in the scientific literature related to the Management of Urban Solid Waste, published in the annals of four relevant Brazilian conferences in the area of Business Administration: ANPAD Meeting (ENANPAD), International Meeting on Management and Environment (ENGEMA), Seminars in Administration (SEMEAD) and Symposium on Administration, Logistics and International Operations (SIMPOI). The data collection considered the period from 2011 to 2016, which reflects the conduct adjustment to meet the requirements of Law No. $12.305 / 2010$, as proposed by the National Solid Waste Policy. The research was carried out through an empirical-analytical study, with application of bibliometric techniques that identified, in the annals of the events, 447 articles referring to Environmental Management and solid waste produced in the municipalities. Of these, $331(73.5 \%)$ referred specifically to solid waste management and were used as a documentary sample for this article. As a result of the analysis of the present study, 45 elements were identified in the management of solid urban waste. These elements were classified into four categories of analysis: Waste Collector Cooperatives, Reverse Logic, National Solid Waste and Waste Policy. Among the conclusions we reached with the content analyzes, we can list: a gradual increase in the discussion on Urban Solid Waste Management in Brazil, since the Law was edited and implemented, which indicates a tendency of the theme to become more explored in the scope national level of academic production, considering its importance in the international environmental debate; observation of ENGEMA as an event that concentrates the highest percentage of Urban Solid Waste Management, reaching 65.86\% of the articles published in the theme; in terms of author's affiliation, there is a predominance of researchers from federal universities located in the South and Northeast regions of Brazil; through the articles, the existence of successful recycling practices, reverse logistics and selective collection.

Keywords: environment management; urban solid waste; bibliometric research; law 12.305/2010.

\section{Introdução}

A Revolução Industrial do século XVIII proporcionou avanços irreversíveis para a sociedade e determinou uma mudança profunda nos hábitos de consumo das pessoas. A possibilidade de produção em larga escala fortaleceu a economia e gerou empregos assalariados; em contrapartida, estabeleceu necessidades cada vez maiores de consumo de recursos naturais (especialmente água e energia), e impulsionou a emissão de gases e resíduos que poluem o meio ambiente. A continuidade desse desenvolvimento industrial até os nossos dias foi fundamental para o desenvolvimento socioeconô- mico, embora tenha intensificado a poluição e a devastação ambiental. As novas técnicas de industrialização, o aumento populacional e o consumismo estimulado pelo capitalismo acabaram por provocar ampla utilização dos recursos naturais e surgimento de uma gama enorme de novos produtos. Como consequência, houve a geração de muitos tipos de resíduos, alguns deles perigosos à saúde humana. Como "atuar no mundo e gerar resíduos são atitudes mutuamente consorciadas" (Waldman, 2010, p. 44), resíduos estiveram presentes desde sempre na civilização humana. Com o grande aumento de resíduos provenientes da industrialização, porém, 
tais detritos se tornaram preocupação mundial, sobretudo a partir da segunda metade do século XX.

No Brasil, de acordo com a Política Nacional de Resíduos Sólidos (PNRS), Lei n ${ }^{\circ}$ 12.305/2010 (Brasil, 2010a), os lixões deveriam ter sido extintos para dar lugar a Aterros Sanitários. Os rejeitos dos resíduos sólidos urbanos (RSU) somente deveriam ser dispostos em aterros quando os RSU não apresentarem potencial de reutilização, o que inclui a logística reversa e a reciclagem de quase todos os materiais. As prefeituras são responsáveis por assegurar o serviço de limpeza pública, incluindo a coleta de resíduos domiciliares e disposição final dos rejeitos dos RSU, de acordo a Lei n ${ }^{\circ}$ 11.445/2007, que instituiu as Diretrizes Nacionais do Saneamento Básico (Brasil, 2007).

Observa-se, nacional e internacionalmente, nas últimas três décadas, um significativo aumento da preocupação voltada à sustentabilidade, haja vista os eventos e movimentos mundiais nesse sentido. Alguns desses eventos são as Convenção das Partes (COPs), relacionadas ao clima, as quais ocorrem anualmente e reúnem centenas de chefes de Estado na busca por formas de desenvolvimento que sejam mais sustentáveis. Nesse sentido, questões relacionadas à preservação do meio ambiente e gestão sustentável foram inseridas na pauta governamental internacional, no meio empresarial, industrial, acadêmico e científico.

As questões ambientais ganharam destaque por parte das produções científicas, pois elencam as medidas que cidadãos, governos, ONGs e empresas estão tomando com relação a essa temática. Um dos meios para se analisar tais questões é a investigação em anais de congressos e outros eventos científicos. Segundo Oliveira (2002), tais publicações desempenham um papel importante na divulgação das pesquisas e no progresso do conhecimento, propiciando uma inigualável e ágil forma de disseminação de discussões acadêmicas acerca de determinados temas. Isso ocorre, pois tais publicações dão suporte cada vez maior para a criação e difusão de avanços, corroborando para o desenvolvimento do País.

Para Cardoso et al. (2005), analisar pesquisas acadêmicas a partir do mapeamento em determinada área por meio de revisões sistemáticas é uma das formas de permitir a avaliação e a reflexão desses trabalhos e da área em questão. Segundo Silva et al. (2005, p. 21) "grande parte da produção científica evidenciada hoje no Brasil é fruto de trabalhos realizados nos cursos de pós-graduação lato sensu e stricto sensu promovidos pelas instituições de ensino superior". Tais estudos desenvolvidos em cursos de pós-graduação focam diferentes temáticas, atendendo a diversos usuários das informações. Nesse sentido, é pertinente o desenvolvimento de pesquisas que tragam luz à agenda ambiental, ao que poderá ser aperfeiçoado para a mitigação dos impactos e ao tratamento das questões ambientais pelas organizações públicas, privadas e do terceiro setor.

Com o intuito de analisar as publicações que contemplam o tema da gestão dos resíduos sólidos urbanos (GRSU) na área científica nos últimos anos, surge a seguinte indagação de pesquisa: qual o perfil dos artigos publicados em eventos nacionais sobre a temática GRSU?

Para atender essa questão de pesquisa, esse estudo analisou a produção de artigos acadêmicos publicados nos anais de quatro dentre os maiores eventos nacionais na área de Administração, área de interesse das pesquisadoras: ENANPAD, ENGEMA, SEMEAD e SIMPOI, no período de 2011 
a 2016. A escolha do período se deu em função de ter ocorrido, no final do ano de 2010, a publicação da PNRS e do Decreto $n^{0} 7.404 / 2010$, que a regulamenta; e 2016, por ser o ano de fechamento da pesquisa. Os objetivos específicos contemplam o levantamento da produção científica quanto aos seguintes aspectos: quantidade de artigos publicados no período estudado; frequência de autoria; vínculo institucional dos autores de tais trabalhos e análise de conteúdo das publicações.

Justifica-se a relevância do estudo pela contribuição de publicações que priorizem o cumprimento da legislação ambiental para disseminar o conhecimento sobre essa temática, essencial para a busca de uma forma de desenvolvimento mais sustentável.

O conceito de Desenvolvimento Sustentável se fortaleceu a partir da Conferência das Nações Unidas sobre o Meio Ambiente e Desenvolvimento (CNUMAD, popularmente conhecida como Rio 92, Eco-92, ou Cúpula da Terra), realizada com representação de 179 países, com o objetivo de identificar a presença ou ausência de políticas que gerem efeitos ambientais negativos. Foi na década de 90 que a sociedade e as organizações passaram a compreender a necessidade da implementação de uma nova visão de desenvolvimento econômico, em um modelo que garantisse a produção de bens e serviços atendendo ao mesmo tempo às necessidades básicas do ser humano e preservando o meio ambiente. Assim, demonstra-se que é possível unir as três variáveis (desenvolvimento, meio ambiente e sociedade) de forma engrenada, nas quais todas poderiam ser beneficiadas (Nascimento et al., 2008).

As bases do Desenvolvimento Sustentável ganharam notoriedade a partir da elaboração de um modelo de gestão mundialmente conhecido como Triple Botton Line (TBL), termo criado por
John Elkington (1994). A tese sustentada por ele é de que os objetivos de qualquer organização estão ligados à ambiência em que atuam, e que suas práticas deveriam considerar os impactos ambientais e sociais para constituir uma relação de eficiência duradoura, observando o tripé People, Planet, Profit (pessoas, planeta, lucro).

Ignacy Sachs (2008) considerou sustentabilidade dentro do conceito de desenvolvimento sustentável, com o objetivo de estabelecer um aproveitamento racional e ecologicamente inteligente da natureza em benefício das populações locais. Isso acaba levando-as a incorporar a preocupação com a conservação da biodiversidade aos seus próprios interesses, como um elemento de estratégia de desenvolvimento, atrelando a isso também questões sociais.

As considerações dos pesquisadores relacionam-se diretamente à GRSU, na medida em que são essenciais para que se coloque em prática o desenvolvimento sustentável.

\section{Gestão de resíduos sólidos urbanos no Brasil - uma das ações necessárias ao desenvolvimento sustentável}

Procurou-se, nessa breve revisão de literatura, focar no construto GRSU, haja vista a importância do tema para a redução dos impactos ambientais e a recente legislação brasileira acerca do assunto, suas diretrizes e objetivos.

Todos os bens de consumo têm, em sua composição, recursos naturais em diferentes etapas de seus ciclos de vida. Por isso, o consumo precisa ser minimizado sem que isso interfira na economia dos países. Esse é o grande desafio, pois, no modelo 
industrial econômico vigente, o consumo acelerado dos recursos naturais para atender a produção de bens e serviços de uma população crescente evidencia a insustentabilidade dos padrões aplicados pela sociedade (Sachs, 1993; Mebratu, 1998; OECD, 2001).

Frente a um modelo econômico que preconiza o consumo de "descartáveis", questiona-se como satisfazer as necessidades presentes preocupando-se com a destinação de resíduos pós-consumo (Silva et al., 2012), os quais não podem mais ser simplesmente descartados: devem, obrigatoriamente, voltar para a cadeia produtiva por meio da logística reversa.

Os resíduos industriais são considerados, na atualidade, externalidades negativas, haja vista a geração de impactos sobre o bem-estar da sociedade, os quais só deixariam de existir caso não houvesse atividade econômica (Pearce \& Turner, 1995). Isso é incompatível com as necessidades produtivas do modelo de desenvolvimento vigente.

Pode-se considerar que resíduos são erros de projeto. Caso os produtos sejam desenhados para aproveitamento ou reaproveitamento total, resíduos deixariam de existir. Já que a geração de resíduos é um reflexo de toda e qualquer atividade, compreender os princípios de sua geração permite avaliar as melhores oportunidades de sua gestão (Silva et al., 2012).A redução da poluição a níveis aceitáveis, em que o custo social não extrapole os benefícios gerados pela atividade, é o ponto principal para o desenvolvimento sustentável (McDougall et al., 2001; ONU, 2015).

A GRSU visa estabelecer diretrizes, metas de controle das fontes geradoras, manejo e promoção dos princípios de minimização de resíduos. Ela está em sintonia com preceitos de saúde pública, ambientais, técnico-operacionais, econômicos, sociais e legais que balizam as ações a serem empregadas no gerenciamento desses resíduos. Pode, por sua vez, ser considerado como o conjunto de ações a serem executadas para efetivar tais metas e diretrizes estabelecidas no modelo proposto (Córdoba, 2010). A PNRS, Lei $n^{\circ} 12.305 / 2010$, em seu artigo $3^{\circ}$, assim define gerenciamento e gestão de RSU:

$\mathrm{X}$ - gerenciamento de resíduos sólidos: conjunto de ações exercidas, direta ou indiretamente, nas etapas de coleta, transporte, transbordo, tratamento e destinação final ambientalmente adequada dos resíduos sólidos e disposição final ambientalmente adequada dos rejeitos, de acordo com plano municipal de gestão integrada de resíduos sólidos ou com plano de gerenciamento de resíduos sólidos, exigidos na forma desta Lei;

XI - gestão de resíduos sólidos: conjunto de ações voltadas para a busca de soluções para os resíduos sólidos, de forma a considerar as dimensões política, econômica, ambiental, cultural e social, com controle social e sob a premissa do desenvolvimento sustentável (Brasil, 2010a, p.2).

O Decreto $n^{\circ} 7.404 / 2010$ regulamenta a PNRS e detalha, em seu artigo 80 , medidas indutoras que poderão ser adotadas pelo Poder Público para motivar o contribuinte a praticar atividades de menor impacto ambiental, estimulando condutas não poluidoras. Dentre tais medidas destacam-se incentivos fiscais, financeiros e creditícios, cessão de terrenos públicos e subvenções econômicas que poderão ser oferecidas para compensar os gastos que a nova lei acaba de impor, principalmente em razão da obrigatoriedade da logística reversa para as empresas, indústrias, distribuidores e comerciantes (Brasil, 2010a).

A importância da PNRS é, portanto, a de orientar nacionalmente a ação governamental na gestão ambiental dos RSU, com o prevê o art. $4^{\mathrm{o}}$ : 
A Política Nacional de Resíduos Sólidos reúne o conjunto de princípios, objetivos, instrumentos, diretrizes, metas e ações adotadas pelo Governo Federal, isoladamente ou em regime de cooperação com os Estados, Distrito Federal, Municípios ou particulares, com vista à gestão integrada e ao gerenciamento ambientalmente adequado dos resíduos sólidos (Brasil, 2010a, p.3).

O descarte irregular de RSU, ainda realizado por muitos municípios brasileiros, contribui diretamente com a poluição do meio ambiente e exige fiscalização e atuação punitiva dos poderes públicos em níveis estadual e federal. Segundo dados da ABRELPE, 30 milhões de toneladas de RSU foram depositados em lixões ou aterros controlados em 2015. Do ponto de vista técnico, tais aterros apresentam os mesmos problemas dos lixões, já que não atendem aos requisitos necessários para a proteção do meio ambiente contra danos e degradações (ABRELPE, 2016).

A PNRS instituiu a regionalização da gestão dos resíduos, por meio de instrumentos de cooperação. Para tanto, prevê em seu artigo 14 a criação do plano nacional, de planos estaduais, microrregionais (ou de regiões metropolitanas ou aglomerações urbanas), planos intermunicipais e o Plano de Gestão Integrada de Resíduos Sólidos Urbanos (PGIRSU, que deve ser municipal ou intermunicipal) (Brasil, 2010a).

Seguindo a PNRS, os municípios, que antes podiam legislar livremente sobre RSU, tiveram que elaborar seu PGIRSU, encerrando seus lixões até 03 de agosto de 2014. Como tal determinação não foi atendida, o prazo acabou prorrogado até 2021, de forma escalonada, por força de Projeto de Lei do Senado (PLS) 425/2014 (Brasil, 2014). O PGIRSU deve ser compatível com a realidade local, contendo um diagnóstico sobre a situação dos resíduos, as metas para redução e para reciclagem e o fim dos lixões a céu aberto, além de buscar soluções consorciadas com outros municípios (Gomes et al., 2014).

Espera-se dos planos, sejam eles municipais ou estaduais, que contemplem o incentivo à reciclagem e geração de emprego e renda para a sua região, já que a PNRS reconhece nas cooperativas de catadores de materiais recicláveis um elo fundamental da cadeia de reciclagem. Ela também recomenda a priorização de parcerias entre empresas e catadores organizados para o sucesso da logística reversa. A Lei prevê, ainda, recursos da União aos municípios que considerem os catadores na matriz da coleta seletiva. O PGIRS, enfim, deve envolver a responsabilidade compartilhada do ciclo de vida dos produtos, principalmente na cadeia de embalagens pós-consumo, como preconizado pela PNRS (Guardabassio, 2014).

Apresentando seus objetivos, a PNRS inova ao regulamentar a priorização de produtos reciclados e recicláveis nas aquisições e contratações governamentais, integração dos catadores de materiais reutilizáveis e recicláveis, estímulo à implementação da avaliação do ciclo de vida do produto, rotulagem ambiental e consumo sustentável (Brasil, 2010a).

No artigo $9^{\circ}$, ao estabelecer suas diretrizes, a PNRS espera que os geradores observem a seguinte ordem de prioridade: a não geração de resíduos, seguida pela política dos 3 Rs (redução, reutilização e reciclagem) e encerrada com o tratamento e a disposição final ambientalmente adequada dos rejeitos (Brasil, 2010a).

Percebe-se, enfim, que a gestão dos RSU deve articular basicamente três aspectos fundamentais: "arranjos institucionais, instrumentos legais e mecanismos de financiamento que organizem o setor 
desde o modelo de planejamento e estratégias de atuação culminando em modelos de execução e medidas de controle e minimização dos resíduos" (Córdoba, 2010, p. 12).

Face ao exposto, optou-se, neste estudo, por analisar publicações acerca da gestão dos RSU, considerados pela PNRS como materiais ou substâncias em estado sólido ou semissólido resultantes de atividades humanas, que são descartados e necessitam de destinação final adequada. Tal assunto é um dos grandes temas contemporâneos debatidos internacionalmente e que ganhou ênfase, no Brasil, desde a promulgação da Lei ${ }^{\circ}$ 12.305/2010 (Carvalho \& Pereira, 2013). A análise realizada procurou, além de quantificar os trabalhos publicados nos eventos e período mencionados, verificar se as publicações são sensíveis às necessidades impostas pelo novo marco legal quanto ao cumprimento de suas diretrizes e objetivos.

\section{Metodologia}

Quanto à abordagem metodológica, o presente estudo pode ser considerado empírico-analítico. No que se refere aos procedimentos técnicos empregados, pode-se classificar como pesquisa bibliométrica, em que se procurou mensurar a frequência dos conteúdos nas publicações.

O objetivo foi o de investigar quais elementos da gestão de RSU são contemplados com mais frequência nas publicações de seis edições dos quatro eventos selecionados, partindo de categorias analíticas estabelecidas a priori e verificando o atendimento às diretrizes e objetivos estabelecidos pela PNRS. São elas: Cooperativas de Catadores; Desenvolvimento Local; Desenvolvimento Regio-

\section{nal; Educação Ambiental; Legislação Ambiental;} Logística Reversa; Políticas Públicas Ambientais; Política Nacional de Resíduos Sólidos; Resíduos.

Conforme sugere Pinto (2013), realizou-se revisão de leitura sistemática, ou seja, metanálise qualitativa, já que não foi objetivo estabelecer correlação. A abordagem da pesquisa é exploratória, pois se pretendeu conhecer o que vem sendo apresentado em quatro dos principais eventos nacionais em Administração (ENANPAD, ENGEMA, SEMEAD e SIMPOI) sobre GRSU desde a publicação da Lei $\mathrm{n}^{\circ}$ 12.305/2010, que estabeleceu uma PNRS para o Brasil.

A bibliometria pode ser conceituada como o estudo dos aspectos quantitativos da produção, disseminação e do uso da informação registrada, tendo os primeiros estudos sido realizados por Pritchard, em 1969 (Balancieri, 2004). Para Fonseca (1986), a bibliometria consiste na aplicação da estatística à bibliografia. Os primeiros estudos bibliométricos em Administração foram publicados a partir das décadas de 1980 e 1990, sendo observados os mais impactantes a partir de 2000. Desde então, o número de publicações desse tipo de estudo vem crescendo devido ao aumento expressivo dos programas de pós-graduação stricto sensu criados - o que gera aumento no número de produção científica na área, não apenas no Brasil, mas no exterior (Leite Filho, 2008).

Há três leis básicas a reger os estudos bibliométricos: Lei de Lotka (produtividade de autores), Lei de Bradford (produtividade de periódicos) e a Lei de Zipf (frequência de ocorrência de palavras). A Lei de Lotka foi desenvolvida a partir das observações acerca da autoria, as quais evidenciam uma larga proporção científica produzida por um reduzido número de autores; isso indica que a produção 
de grande número de pequenos autores se iguala à mesma produção de um pequeno número de grandes autores (Araújo, 2006). Guedes \& Borschiver (2005, p. 3) mencionam que a Lei de Bradford "permite estimar o grau de relevância de periódicos em dada área do conhecimento, que os periódicos que produzem o maior número de artigos sobre dado assunto formam um núcleo de periódicos, supostamente de maior qualidade ou relevância para aquela área". Infere-se aqui que o mesmo se dá em relação a publicações em anais de eventos científicos, que primeiramente apresentam as publicações à comunidade acadêmica, objetivando suscitar discussões e receber importantes contribuições. As informações contidas em anais poderão complementar estudos que serão posteriormente publicados em periódicos científicos qualificados. E, por fim, A Lei de Zipf descreve que é possível analisar a frequência de palavras de um determinado texto científico e tecnológico (Araújo, 2006). O presente estudo utilizou-se das três leis bibliométricas em razão da percepção de sua riqueza informativa e analítica para a abordagem do tema GRSU.

Antes de se proceder à busca do material nos eventos e período selecionados, foram estabelecidas as categorias que seriam utilizadas na pesquisa.

Estabelecidas as nove categorias mencionadas, procedeu-se à busca de artigos nos quatro eventos selecionados (ENANPAD, ENGEMA, SEMEAD e SIMPOI) em seis edições (2010-2016).

Na busca realizada, apurou-se um número inicial de 447 trabalhos relacionados às nove categorias.

Os quatro eventos pesquisados possuem área de interesse voltada para a temática ambiental. Em 2016, edição de fechamento da presente pesquisa, o ENANPAD contou com três divisões acadêmicas, cada uma delas contemplando a área ambiental agregada a outro campo de pesquisa organizacional, como estratégia, inovação e operações/logística. O ENGEMA, específico para a questão ambiental, é dividido em quatro grandes áreas temáticas, cada uma delas dividida em diversos temas de interesse de pesquisa. O SEMEAD trouxe a gestão socioambiental como área de interesse. O SIMPOI trouxe a temática ambiental na área intitulada sustentabilidade das operações, dividida em seis subáreas.

Todo o conteúdo de informações disponibilizado reforça a importância dos eventos como fonte de acesso às pesquisas mais recentes realizadas em Administração, especificamente, para o presente estudo, na temática GRSU.

Foram pesquisados, nos anais dos eventos em questão, artigos em cujo título, resumo, palavras-chave ou no próprio texto, houvesse referência às categorias supracitadas. Quando encontradas duas ou mais dessas palavras ou termos de pesquisa em um mesmo artigo, estes foram considerados uma única vez.

Numa última etapa, os artigos foram separados e analisados para apurar número de autores, instituição de vínculo e elementos acerca das categorias predefinidas.

\section{Resultados e Discussão}

\subsection{Características gerais das publicações}

\subsubsection{Artigos por evento e por ano de publicação}

Após criteriosa busca nos anais dos referidos eventos, foram encontrados 447 artigos sobre gestão 
ambiental, tomando-se por base o período de 20112016 e as categorias previamente definidas.

Observa-se um aumento gradativo, ano a ano, no volume de artigos com a temática da gestão ambiental se somados os quatro eventos pesquisados; observa-se, também, que o ENGEMA se destaca dos demais eventos quanto à quantidade de trabalhos publicados (285) acerca do tema no período pesquisado, respondendo por mais da metade de todo o conjunto. Isso se deve ao fato de que tal evento tem foco específico em gestão e meio ambiente. Em segundo lugar está o SEMEAD, com 75 artigos, seguido pelo ENANPAD, com 49 artigos relacionados à presente pesquisa e, por último, o SIMPOI, com 38 trabalhos.

Quanto às categorias pesquisadas, no conjunto dos quatro eventos e no período compreendido (2011-2016), o resultado obtido foi o seguinte: a categoria Cooperativas de Catadores traz 52 resultados; Desenvolvimento Local, oito resultados; Desenvolvimento Regional, 24 resultados; Educação Ambiental aparece em 54 artigos; Legislação Ambiental, em apenas 10; Logística Reversa traz um resultado significativo, com 99 aparições; Políticas Públicas Ambientais aparece 20 vezes; Política Nacional de Resíduos Sólidos 26 vezes e, finalmente, Resíduos, com o expressivo resultado de 154 aparições, o maior dentre todos os termos pesquisados.

Em que pese o significativo volume de artigos inicialmente obtido, como o presente trabalho se propõe a investigar os artigos publicados com a temática da gestão de RSU, depois da primeira busca com as nove categorias já destacadas e a obtenção de 447 trabalhos, houve necessidade de se proceder a um refinamento da pesquisa. Assim, nos restringimos a apenas quatro categorias, que refletem propriamente o objeto do presente estudo: Cooperativas de Catadores, Logística Reversa, Política Nacional de Resíduos Sólidos e Resíduos, desprezando-se as demais, já que não especificamente ligadas à gestão de RSU. Dessa forma, foram desprezados 116 artigos inicialmente encontrados.

O resultado obtido é evidenciado na Tabela 1, que aponta a incidência das categorias após o refinamento realizado.

TABELA 1 - Distribuição das categorias por evento e por período.

\begin{tabular}{|c|c|c|c|c|c|c|c|c|c|c|}
\hline \multirow{3}{*}{ Categoria } & \multirow{2}{*}{\multicolumn{2}{|c|}{$\begin{array}{l}\text { ENANPAD } \\
2011-2016\end{array}$}} & \multirow{2}{*}{\multicolumn{2}{|c|}{$\begin{array}{c}\text { ENGEMA } \\
2011 \text { - } 2016\end{array}$}} & \multirow{2}{*}{\multicolumn{2}{|c|}{$\begin{array}{c}\text { SEMEAD } \\
2011-2016\end{array}$}} & \multirow{2}{*}{\multicolumn{2}{|c|}{$\begin{array}{c}\text { SIMPOI } \\
2011 \text { - } 2016\end{array}$}} & \multirow{2}{*}{\multicolumn{2}{|c|}{$\begin{array}{c}\text { Total } \\
2011-2016\end{array}$}} \\
\hline & & & & & & & & & & \\
\hline & Quant. & $\%$ & Quant. & $\%$ & Quant. & $\%$ & Quant. & $\%$ & Quant. & $\%$ \\
\hline $\begin{array}{l}\text { Cooperativa de } \\
\text { Catadores }\end{array}$ & 9 & 29,03 & 28 & 12,84 & 11 & 24,44 & 4 & 10,81 & 52 & 15,71 \\
\hline PNRS & 3 & 9,68 & 18 & 8,26 & 4 & 8,89 & 1 & 2,70 & 26 & 7,85 \\
\hline Resíduos & 10 & 32,26 & 106 & 48,62 & 18 & 40 & 20 & 54,05 & 154 & 46,53 \\
\hline Total de artigos & 31 & 100 & 218 & 100 & 45 & 100 & 37 & 100 & 331 & 100 \\
\hline
\end{tabular}

FONTE: Elaborado pelas autoras (2018). 
A Tabela 1 ratifica a prevalência quantitativa do ENGEMA sobre os demais eventos pesquisados e evidencia a maior incidência da categoria Resíduos dentre os quatro eventos (154 no total), seguida por Logística Reversa (com 99 aparições) e, em terceiro lugar, Cooperativas de Catadores (com 52 aparições). A Figura 1 apresenta esses dados sob a forma de gráfico que mostra os percentuais referentes a cada categoria e evento.

Observando-se o gráfico apresentado na Figura 1, percebe-se que os eventos ENGEMA e SIMPOI, de caráter interdisciplinar, tiveram mais artigos publicados relacionados a Resíduos e a Logística Reversa que os demais, voltados para a área de Administração. Estes tiveram mais artigos com foco em cooperativas de catadores e na PNRS.

Vale destacar que tais categorias estão diretamente ligadas à gestão de RSU, muito mais do que as demais inicialmente pesquisadas e, por esse motivo, procedeu-se o refinamento mencionado. Também apontamos que a busca pela categoria Política Nacional de Resíduos Sólidos mostrou resultados muito acanhados, se considerada a importância do tema no período pesquisado (2011-2016), que coincide com a implementação da lei que institui a política nacional de resíduos no Brasil.

\subsubsection{Artigos por categoria pesquisada após o refinamento}

Depois de selecionados, os 331 trabalhos foram classificados de acordo com a incidência da categoria pesquisada, evento e ano. A Tabela 2 apresenta os principais resultados encontrados após leitura e análise de cada artigo.

\section{Resíduos}

PNRS

Logística Reversa

Cooperativa de Catadores
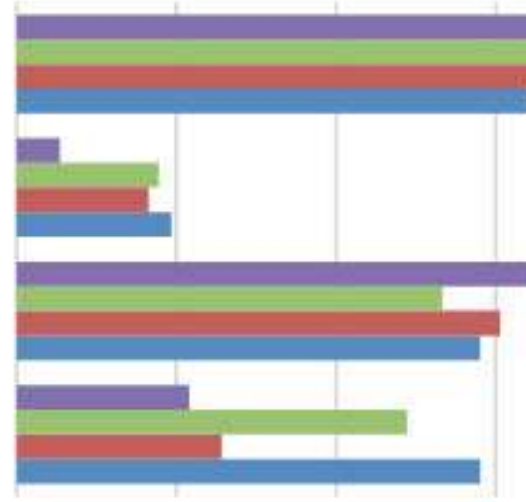

0

10

20

30

40

50

60

\section{ENANPAD ENGEMA IIIIEMEAD}

FIGURA 1 - Distribuição percentual das categorias por evento no período 2011 a 2016.

FONTE: Elaborado pelas autoras (2018). 
De forma mais visual, a Figura 2 apresenta esses dados em gráfico.

Pode-se observar que o evento que mais publicou sobre as categorias pesquisadas foi o ENGEMA, possivelmente pelo caráter multidisciplinar, uma vez que as categorias de análise são de interesse não só de administradores, mas também de engenheiros, dentre outras profissões.

O resultado obtido, somando-se os artigos encontrados nos eventos e período pesquisados, tendo por base as quatro categorias destacadas, foi de 331 artigos distribuídos da seguinte maneira: 31 artigos

TABELA 2 - Distribuição dos artigos por evento e por ano.

\begin{tabular}{|c|c|c|c|c|c|c|c|c|}
\hline Evento & \multicolumn{6}{|c|}{ Ano } & Total & $\begin{array}{c}\text { Participação } \\
\%\end{array}$ \\
\hline ENANPAD & 7 & 4 & 4 & 7 & 4 & 5 & 31 & 9,36 \\
\hline ENGEMA & 20 & 29 & 38 & 43 & 40 & 48 & 218 & 65,86 \\
\hline SEMEAD & 7 & 7 & 7 & 9 & 10 & 5 & 45 & 13,6 \\
\hline Total & 42 & 45 & 57 & 63 & 59 & 65 & 331 & 100 \\
\hline
\end{tabular}

FONTE: Elaborado pelas autoras (2018).

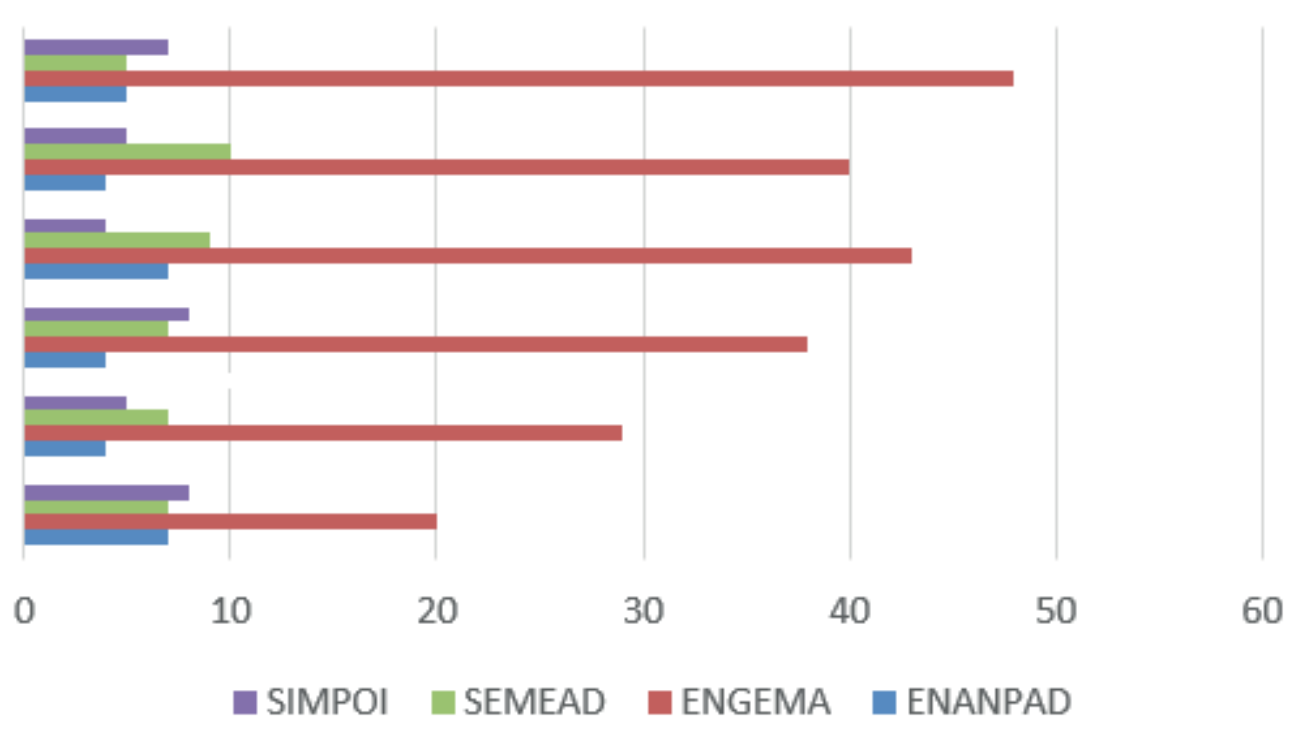

FIGURA 2 - Distribuição dos artigos por evento e por ano. 
no ENANPAD, 218 no ENGEMA, 45 no SEMEAD e 37 no SIMPOI. Com este resultado, o ENGEMA continua respondendo por mais da metade dos trabalhos ( $65,86 \%$ do total), seguido pelo SEMEAD na segunda posição $(13,60 \%)$, SIMPOI na terceira $(11,18 \%)$ e, por último, o ENANPAD $(9,36 \%)$, que ocupara a terceira posição na primeira busca.

Observa-se também uma evolução gradual na participação da temática GRSU nos quatro eventos pesquisados, notadamente a partir da edição de 2014, quando os eventos pesquisados somaram 63 publicações (com destaque para o ENGEMA e o SEMEAD). Em 2015, relacionados às categorias pós-refinamento, foram 59 artigos identificados nos quatro eventos. Tal número aumentou em 2016, com 65 artigos, destacando-se novamente o ENGEMA, com 48 trabalhos nesta edição. Não há alteração significativa na participação da temática RSU se considerada a evolução anual do ENANPAD, que se mantém praticamente estável nas seis edições pesquisadas: sete artigos em 2011, quatro em 2012 e 2013, sete em 2014 e novamente quatro em 2015 e cinco em 2016. O mesmo ocorreu com o SIMPOI, que apresentou oito artigos em 2011, cinco em 2012, oito em 2013, quatro em 2014, cinco em 2015 e sete em 2016.

Observados separadamente, os resultados encontrados são apresentados no texto a seguir:

\subsubsection{Número de autores e respectivas instituições a que se vinculam}

A partir das informações divulgadas quanto às instituições de vinculação e número de autores, identificou-se que mais da metade dos trabalhos provêm de autores ligados a Universidades Federais (65\%), com destaque para as instituições listadas a seguir: Universidade Federal do Rio Grande do Sul (UFGRS), com 13,3\% dos autores de trabalhos; Universidade Federal de Santa Maria (UFSM), com 11,6\%; Universidade Federal de Uberlândia (UFU), com 9,0\%; Universidade Federal de Campina Grande (UFCG), com 6,2\%. Dentre as Estaduais, destacamos Universidade de São Paulo (USP), com $11,7 \%$ e Universidade Estadual Paulista Júlio de Mesquita Filho (UNESP), com 9,5\%. Dentre as universidades particulares, destacam-se a Universidade FEEVALE, com 13,3\%, a Universidade Nove de Julho (UNINOVE), com 12,5\%, o Centro Universitário FEI, com 10,9\%, a Fundação Getúlio Vargas (FGV), com 10,4\%, e a Universidade Municipal de São Caetano do Sul (USCS), com 5,2\% dos trabalhos pesquisados. Quanto ao número de autores, observou-se que preponderam, dentre os trabalhos publicados pelas Universidades Federais, os de dois autores (32\%) e três autores (20\%), seguidos pelos trabalhos realizados por cinco, quatro e um único autor, com $16 \%$ para cada categoria. O mesmo fenômeno é observado nos trabalhos cujos autores provêm de Universidades Públicas Estaduais, com preponderância dos artigos de dois e três autores. Nas instituições particulares, finalmente, também prevalecem os artigos produzidos por três autores (36\% do total), seguidos pelos trabalhos produzidos por dois, quatro autores e um autor, respectivamente, com $28 \%, 17 \%$ e $12 \%$. Tradicionalmente, as Universidades Federais registram maior participação nos eventos do País, especialmente no Sul/Sudeste.

\subsubsection{Conteúdo dos artigos sobre RSU por evento}

Quando analisados os conteúdos desses 331 textos pós-refinamento, observou-se que, dos 31 
artigos selecionados no ENANPAD na categoria resíduos, foram localizados 10 artigos. Dentre esses, 3 tratam de resíduos eletroeletrônicos (REE), 1 de resíduos de serviço de saúde (RSS), 2 de resíduos de construção e demolição (RCD), 2 de produção mais limpa $(\mathrm{P}+\mathrm{L}), 1$ de créditos de carbono em aterros sanitários e 1 a respeito de evidenciação ambiental no ramo de papel e celulose. Pesquisada a categoria cooperativa de catadores no ENANPAD, chegamos ao resultado de 9 artigos: em 6 deles, evidencia-se o tema catadores, 1 trata da reciclagem de papel. 1 da reciclagem de RCD e 1 de aprendizagem em rede no setor de reciclagem. Pesquisada a categoria logística reversa (LR), ainda no ENANPAD, foram encontrados nove artigos: 2 deles tratam de pneumáticos, 2 de LR em associações de reciclagem, 1 sobre retorno do óleo de cozinha usado, 1 a respeito de briquetes, 1 sobre a LR pós-consumo no setor supermercadista, 1 acerca da LR de resíduos de informática e 1 sobre a LR de vidros de esmalte. Quanto à categoria $P$ NRS, foram obtidos 3 artigos no referido evento:1 sobre a PNRS e os canais institucionais de participação na gestão pública municipal, 1 sobre a LR de medicamentos no Brasil à luz da PNRS e 1 sobre o monitoramento e difusão de informações sobre RSU para atendimento dos objetivos e metas da PNRS.

No evento SEMEAD, 45 artigos foram selecionados a partir da pesquisa das mesmas quatro categorias pós-refinamento. A categoria resíduos aparece em 18 artigos, 3 deles sobre $\mathrm{P}+\mathrm{L}, 3$ sobre RSS, 5 sobre Gestão de Resíduos Sólidos Urbanos (GRSU), 3 sobre RCD, 1 sobre REE, 1 sobre resíduos no setor de food service e 1 sobre coleta seletiva e um a respeito da agenda ambiental na administração pública. A categoria cooperativas de catadores apresentou 11 resultados, com 6 artigos sobre cooperativas de catadores; 1 acerca de reciclagem numa empresa de brindes; 1 sobre reciclagem na indústria de água mineral; 1 a respeito de práticas sustentáveis em farmácias; 1 sobre reciclagem em indústrias químicas; 1 sobre fluxos reversos de resíduos de equipamentos eletroeletrônicos (REEE). Pesquisada a categoria logística reversa, foram encontrados 12 artigos: 2 deles tratam da LR no setor de pneumáticos; 3 de LR pós-venda de REE; 2 de LR na construção civil; 1 da LR no setor de biotecnologia; 1 aborda a temática do óleo residual vegetal; 1 trata de embalagens vazias de agrotóxicos; 2 discutem a LR no setor supermercadista. A categoria $\boldsymbol{P N R S}$ forneceu 4 resultados no referido evento, 1 versando sobre os impactos nas prestadoras de serviço de coleta, 1 acerca da tecnologia de radiofrequência e 2 sobre o descarte de celulares.

No ENGEMA foram encontrados 218 artigos no período pesquisado, distribuídos da seguinte maneira: a categoria resíduos aparece em 106 artigos, abrangendo aspectos no tocante a reciclagem, redução e manejo, relacionando-se aos resíduos industriais, de construção e demolição, de serviços de saúde, gerados em navio e o contexto portuário, de poços de petróleo, resíduos gerados na copa do mundo, de atividades turísticas, do setor hoteleiro, resíduos de equipamentos eletroeletrônicos, coleta seletiva e saúde e segurança ocupacional na triagem dos resíduos. Por sua vez, 66 trataram de logística reversa, relacionados à análise das redes de reciclagem do óleo de cozinha, embalagens PET, lâmpadas fluorescentes do metrô de São Paulo, manufatura de cartuchos, pilhas, baterias, resíduos industriais, captação de biogás em aterros sanitários, embalagens de agrotóxicos e resíduos sólidos urbanos. $\mathrm{Na}$ categoria cooperativa de catadores, 28 abordaram o cooperativismo, desde atuação das cooperativas de 
reciclagem, coleta seletiva até geração de trabalho e renda. Na pesquisa com $\boldsymbol{P N R S}$ foram encontrados 18 artigos, todos eles tratando do amparo legal e da importância da lei na gestão dos RSU.

O SIMPOI traz 37 artigos no período pesquisado, assim distribuídos: 20 que contêm a palavra resíduos, abrangendo aspectos relacionados a reciclagem, redução, não geração, disposição e tratamento, relacionando-se com construção civil, serviços de saúde, eletrodomésticos, pneus e embalagens de vidro; 12 apresentam o termo logística reversa relacionado aos aspectos de resíduos recicláveis, com grande ênfase em custos, e abordando também a necessidade de existência de incentivos fiscais que favoreçam a logística reversa no setor industrial. Por sua vez, 4 artigos tratam de cooperativa de catadores, sempre enfatizando a importância desse trabalhador para que a reciclagem de resíduos, sobretudo os provenientes de domicílios. Por fim, em relação à $\boldsymbol{P N R S}$, um único dos textos desse evento trata do tema, sempre enfatizando a importância da legislação e a necessidade de adaptação nacional a ela.

\subsection{Tabela de elementos e discussão dos resultados}

A Tabela 3 sistematiza as informações coletadas, evidenciando a categorização dos elementos.

$\mathrm{Na}$ categoria cooperativas de catadores o elemento de maior destaque foi "coleta seletiva", sucedido por "materiais recicláveis", "saúde/riscos" e "cooperativismo", respectivamente. A "coleta seletiva", presente em 105 dos 331 artigos analisados, está em consonância com uma das diretrizes da PNRS. O elemento "materiais recicláveis", que aparece com frequência absoluta de 100 artigos, também encontra amparo na PNRS ao definir reciclagem como "o processo de transformação dos resíduos sólidos que envolve a alteração de suas propriedades

TABELA 3 - Identificação dos elementos e classificação por categoria de análise.

\begin{tabular}{clcc}
\hline Categoria & Elementos & $\begin{array}{c}\text { Frequência } \\
\text { nos } \\
\text { artigos }\end{array}$ & $\begin{array}{c}\text { Participação/artigos } \\
\text { \% }\end{array}$ \\
\cline { 2 - 4 } & Coleta seletiva & 105 & 31,72 \\
& Materiais recicláveis & 100 & 30,21 \\
& Saúde/Riscos & 78 & 23,56 \\
& Cooperativismo & 76 & 22,96 \\
& Economia solidária & 79,63 \\
& Trabalho e renda & 65 & 16,01 \\
& Inclusão social & 53 & 15,1 \\
& Catadores autônomos & 50 & 11,17 \\
& Gestor público/munícipes & 37 & 10,87 \\
& Poder público municipal & 3,64 \\
& Cidadania & 36 & 4,22 \\
\hline
\end{tabular}




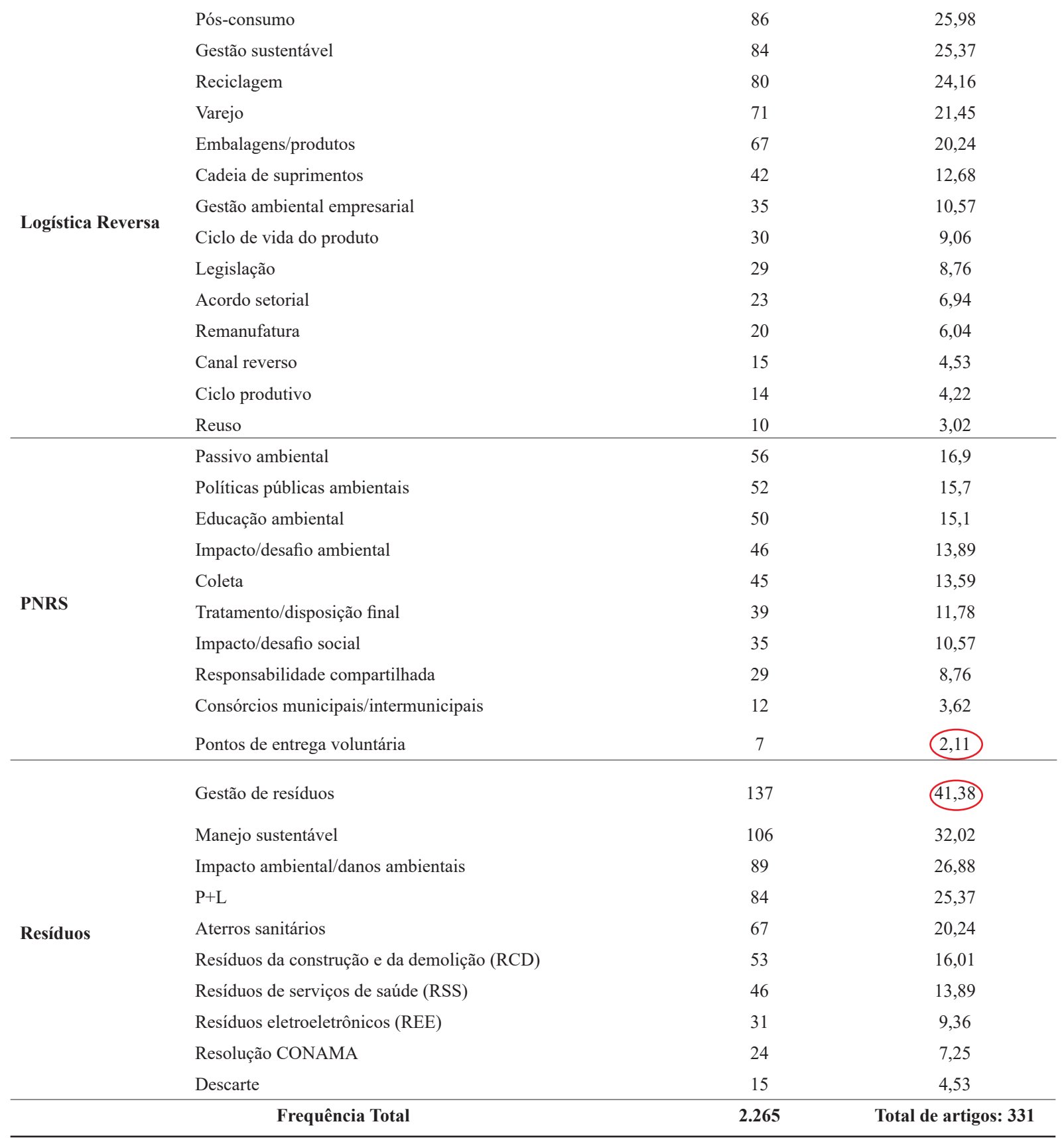

FONTE: Elaborado pelas autoras (2018). 
físicas, físico-químicas ou biológicas, com vistas à transformação em insumos ou novos produtos[...]" (Brasil, 2010a, p.2). A Figura 3 mostra a proporção de cada elemento em relação a todos os elementos dessa categoria.

Na categoria logística reversa, que se tornou obrigatória com a aprovação da PNRS, o elemento de maior destaque, com 86 aparições, foi o "pós-consumo". Tal elemento se refere ao estágio de produtos, bens ou embalagens que atingiram o fim do ciclo de vida útil ou que são descartados antes dele. O grande desafio que a PNRS impõe é a destinação adequada desses materiais que se acumulam muitas vezes em locais públicos ou de mananciais de água, trazendo graves riscos ao meio ambiente e à saúde pública.

Em segunda e terceira posições aparecem os elementos "gestão sustentável" " "reciclagem", com 84 e 80 aparições, respectivamente. Nos trabalhos analisados, são citados com muita frequência relatos de experiências bem-sucedidas com o reaproveitamento do óleo de cozinha, pneus inservíveis, garrafas pet, lâmpadas, baterias, além dos resíduos eletroeletrônicos - setor esse que é obrigado, pela PNRS, a implementar a logística reversa com a responsabilidade compartilhada, incluindo as cooperativas de catadores.

O elemento "varejo", presente em 71 dos artigos analisados, traz com frequência a preocupação pela adoção da logística reversa de embalagens como forma de obter benefícios econômicos, sociais e ambientais com a redução dos resíduos.

Na categoria PNRS os elementos "passivo ambiental", "políticas públicas ambientais" e "educação ambiental", respectivamente, com 56, 52 e 50 aparições, refletem diretamente a nova configuração trazida pela legislação atual, já que, a partir da regulamentação da Lei, os municípios assumem a missão de adotar novas práticas ambientais relacionadas à coleta e destinação dos resíduos. Assim, os prefeitos passam a ser os principais agentes desta mudança, já que, de acordo com a Lei Nacional de Saneamento Básico (LNSB), os municípios são os responsáveis pelos resíduos gerados em seus territórios (Brasil, 2007). Nesse novo cenário, a educação ambiental, um dos patamares da PNRS, passa a ser fundamental para que as pessoas e as comunidades possam examinar criticamente tecnologias, sistemas de produção econômica, sistemas culturais de reprodução, leis e política, ideias e ideologias empregadas atualmente, a fim de viver em harmonia com o resto da natureza. Isso permite, também, reflexão e atuação política a partir de alternativas viáveis (Huckle, 2014).

Por fim, a categoria resíduos trouxe os seguintes elementos com maior destaque: "gestão de resíduos", "manejo sustentável", "impacto ambiental/ danos ambientais", respectivamente, com 137, 106 e 89 aparições. Esse resultado corrobora com as exigências impostas pela PNRS, que se direcionam ao gerenciamento ambientalmente adequado dos resíduos em geral.

Os artigos analisados trazem, majoritariamente, preocupação com os RCD, RSS e REE, com 53, 46 e 31 aparições respectivamente, em razão dos impactos negativos que trazem ao meio ambiente e à saúde pública. Tais trabalhos permitem concluir que as políticas existentes surgiram, em grande maioria, apenas depois da implementação da PNRS, e passam a exigir da população e dos gestores públicos conscientização e apoio para que possam atingir os resultados preconizados e esperados na busca da gestão ambientalmente sustentável. 
Importante destacar que todas as pesquisas analisadas demonstram preocupação quanto à necessidade de atendimento das diretrizes impostas pela legislação, sejam Resoluções CONAMA, da PNRS, bem como do Decreto que a regulamenta. Expõem também, muitas vezes, as dificuldades e obstáculos encontrados na consecução desses objetivos.

\section{Economia solidária Saúde Riscos \\ Cooperativismo
Inclusão social Coleta seletiva \\ Gestor público municipes}

FIGURA 3 - Categoria Cooperativa de Catadores.

FONTE: elaborado pelas autoras (2018).

\section{Varejo cadeia de suprimentos Pós consumo \\ Embalagens produtos

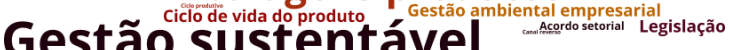 Reciclagem}

FIGURA 4 - Categoria Logística Reversa.

FONTE: Elaborado pelas autoras (2018).

Educação ambiental

Impacto desafio ambiental

Tratamento disposição final

Políticas públicas ambientais

Passivo ambiental

FIGURA 5 - Categoria PNRS.

FONTE: Elaborado pelas autoras (2018).

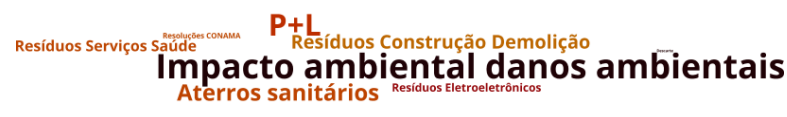

FIGURA 6 - Categoria PNRS.

FONTE: Elaborado pelas autoras (2018).

\section{Conclusão}

A temática ambiental tem conquistado cada vez mais espaço como área de pesquisa, o que reflete no aumento da produção acadêmica em importantes eventos acadêmico-científicos.

Assim, a presente pesquisa objetivou analisar a produção de artigos acadêmicos publicados nos anais de quatro importantes eventos nacionais na área de Administração (ENANPAD, ENGEMA, SEMEAD e SIMPOI), considerado o período de 2011-2016, buscando evidenciar pesquisas que discutiram a GRSU.

Dos eventos pesquisados, observa-se que o ENGEMA é o que apresenta o maior número de artigos abordando a temática GRSU, no período pesquisado $(65,86 \%)$, com preponderância das edições de 2014 e 2016 sobre as anteriores.

Se observados os eventos quanto às categorias pesquisadas, o termo resíduos se destaca em muito sobre as demais, tanto se considerado o evento ENGEMA isoladamente, como se considerado o conjunto de eventos no período de seis anos pesquisado.

Além disso, as categorias que se referem especificamente à gestão de RSU, notadamente Cooperativas de Catadores, Logística Reversa, Política Nacional de Resíduos Sólidos e Resíduos têm preponderância sobre as demais selecionadas, na somatória das seis edições pesquisadas.

No que se refere ao vínculo institucional, a presente pesquisa mostrou predominância de autores ligados a Universidades Federais do Sul e do Nordeste brasileiros.

A PNRS preconiza que os municípios brasileiros eliminem os lixões existentes, colocando o Brasil em patamares parecidos com os dos países 
desenvolvidos, a respeito da reciclagem, reutilização na LR e na coleta seletiva. A PNRS orienta os entes governamentais a uma correta gestão pública dos resíduos sólidos, e, no conteúdo dos 331 artigos analisados, observa-se que existem muitas práticas exitosas nesse sentido.

O sucesso das experiências apresentadas em diversos artigos analisados requer das prefeituras municipais o comprometimento com a inclusão social dos catadores, a inserção efetiva desses agentes nos programas de coleta seletiva, além do reconhecimento das dimensões sociais e ambientais como forma de se alcançar o desenvolvimento que se sustente ao longo do tempo.

As soluções para a questão ambiental nos países em desenvolvimento devem também gerar empregos e promover a participação social. Cabe destacar a importância da conscientização e educação para a reciclagem, pois é pelo consumidor que se inicia a logística reversa.

A responsabilidade compartilhada é prevista como princípio no texto da Lei $n^{\circ} 12.305 / 2010$ PNRS e, como tal, não incide apenas sobre os serviços públicos, mas sobre toda e qualquer atividade pública ou privada, que venha gerar ou influenciar aspectos ambientais relativos a resíduos sólidos. A responsabilidade é de todos os stakeholders envolvidos, direta ou indiretamente no ciclo de vida dos produtos.

O gerador dos resíduos, mesmo não sendo mais o seu proprietário, continua ambientalmente responsável. O mais importante é que a vida útil de um determinado produto não termine após ser consumido, mas que esse produto volte ao seu ciclo de vida para reutilização ou reaproveitamento, ou que o produto tenha uma destinação ambiental correta para minimizar os impactos causados ao meio ambiente. Essa ação irá acontecer por meio da coleta seletiva que, com incentivo dos governos locais, fortalecerá as cooperativas e associações de reciclagem - fundamentais para a GRSU.

A economia não oferece oportunidade equânime para a sobrevivência de pessoas que estão em condições de desigualdade social, mas observa-se que elas encontram no cooperativismo uma forma de viver, potencializando ações de pessoas simples em empreendimentos com objetivos socioeconômicos. Dessa maneira, constata-se um resgate da cidadania e promoção do desenvolvimento econômico, ambiental e social pelo apoio de políticas públicas municipais necessárias ao sucesso da GRSU.

No que concerne à questão de pesquisa "qual o perfil dos artigos publicados em eventos nacionais sobre a temática gestão ambiental de RSU?", conclui-se que as pesquisas sobre essa temática têm aumentado gradativamente nos últimos anos, período que coincide com o surgimento da PNRS, por meio da Lei $\mathrm{n}^{\circ} 12.305 / 2010$ e tendem a ganhar cada vez mais espaço na produção acadêmica nacional, haja vista sua importância no cenário nacional e internacional.

Esta pesquisa contribui para o avanço tanto no que se refere a estudos bibliométricos sobre GRSU, quanto para ressaltar os conteúdos a eles relacionados. Como limitações deste trabalho podem-se apontar a restrição da pesquisa a somente quatro dentre os principais eventos brasileiros da área de Administração, a delimitação temporal de seis anos, a não comparação com os anos anteriores à PNRS. Nossa opção pela análise de artigos publicados em anais de eventos científicos poderá, num próximo estudo, ser ampliado para artigos nacionais e internacionais publicados em periódicos científicos, possibilitando uma maior abrangência da investigação. 


\section{Referências}

ABRELPE - Associação Brasileira de Empresas de Limpeza Pública e Resíduos Especiais. 2016. Panorama dos Resíduos Sólidos no Brasil 2015. Disponível em: <http:// www.abrelpe.org.br/Panorama/panorama2015.pdf $>$. Acesso em: nov. 2016.

ANPAD - Associação Nacional de Pós-graduação em Administração. Anais do XXXV ENANPAD. Rio de Janeiro, 2011.

ANPAD - Associação Nacional de Pós-graduação em Administração. Anais do XXXVI ENANPAD. Rio de Janeiro, 2012.

ANPAD - Associação Nacional de Pós-graduação em Administração. Anais do XXXVII ENANPAD. Rio de Janeiro, 2013.

ANPAD - Associação Nacional de Pós-graduação em Administração. Anais do XXXVIII ENANPAD. Rio de Janeiro, 2014.

ANPAD - Associação Nacional de Pós-graduação em Administração. Anais do XXXIX ENANPAD. Belo Horizonte, 2015.

ANPAD - Associação Nacional de Pós-graduação em Administração. Anais do XXXIX ENANPAD. Costa do Sauipe, 2016.

Araújo, C. A., Bibliometria: evolução histórica e questões atuais. Revista em Questão, 12(1), 11-32, 2006.

Balancieri, R. Análise de redes de pesquisa em uma plataforma de gestão em ciência e tecnologia: uma aplicação à plataforma lattes. 2004. 117 f. Tese (Doutorado em Engenharia da Produção) - Universidade Federal de Santa Catarina, Florianópolis, 2004.

Brasil. Ministério do Meio Ambiente. Lei 11.445/07. Lei Nacional para o Saneamento Básico - LNSB. 2007. Disponível em: <http://www.planalto.gov.br/ccivil_03/_ato20072010/2007/lei/111445.htm>. Acesso em: dez. 2015.

Brasil. Lei 12.305/10. Política Nacional de Resíduos Sólidos. 2010a. Disponível em: <http://www.planalto.gov.br/ ccivil_03/_ato2007-2010/2010/lei/112305.htm>. Acesso em: jan. 2016 .
Brasil. Ministério do Meio Ambiente. Decreto 7404/10. Regulamenta a Lei no 12.305, de 2 de agosto de 2010, que institui a Política Nacional de Resíduos Sólidos, cria o Comitê Interministerial da Política Nacional de Resíduos Sólidos e o Comitê Orientador para a Implantação dos Sistemas de Logística Reversa. 2010b. Disponível em: <http:// www.planalto.gov.br/ccivil_03/_ato2007-2010/2010/decreto/d7404.htm>. Acesso em: set. 2015.

Brasil. Senado Federal. PLS 425/2014. Prorroga o prazo para a disposição final ambientalmente adequada dos rejeitos de que trata o art. 54 da Lei ${ }^{\circ} 12.305$, de 2 de agosto de 2010. Disponível em: $<$ https://www25.senado. leg.br/web/atividade/materias/-/materia/119536 $\geq$. Acesso em: mar. 2018.

Cardoso, R. L.; Mendonça Neto, O. R.; Riccio, E. L.; Sakata, M. C. G. Pesquisa científica em contabilidade entre 1990 e 2003. Revista de Administração de Empresas, 5(1), 2005.

Carvalho, P. P.; Pereira, R. S. Resíduos de Equipamentos Eletroeletrônicos. In. Pereira, R. S. (Org.). Gestão para o desenvolvimento sustentável: Desafios e proposições para a Sustentabilidade Socioambiental. São Paulo: Globus, 2013. p.1-14.

Córdoba, R. E. Estudo do sistema de gerenciamento integrado de resíduos de construção e demolição do município de São Carlos. 2010. 406f. Dissertação (Mestrado em Engenharia Hidráulica e Saneamento) - Escola de Engenharia de São Carlos, Universidade de São Paulo, São Carlos, 2010.

ENGEMA - Encontro Internacional sobre Gestão Empresarial e Meio Ambiente. Anais do XIII ENGEMA. São Paulo, 2011.

ENGEMA - Encontro Internacional sobre Gestão Empresarial e Meio Ambiente. Anais do XIV ENGEMA. São Paulo, 2012.

ENGEMA - Encontro Internacional sobre Gestão Empresarial e Meio Ambiente. Anais do XV ENGEMA. São Paulo, 2013.

ENGEMA - Encontro Internacional sobre Gestão Empresarial e Meio Ambiente. Anais do XVI ENGEMA. São Paulo, 2014.

ENGEMA - Encontro Internacional sobre Gestão Empre- 
sarial e Meio Ambiente. Anais do XVII ENGEMA. São Paulo, 2015.

ENGEMA - Encontro Internacional sobre Gestão Empresarial e Meio Ambiente. Anais do XVII ENGEMA. São Paulo, 2016.

Elkington, J. Canibais com garfo e faca: Seria um progresso se um canibal utilizasse garfo e faca para comer? Tradução: Patrícia Martins Ramalho. São Paulo: Makron Books, 1994.

Fonseca, E. N. Bibliometria: teoria e prática. São Paulo: Cultrix, 1986.

Guedes, V. L. S.; Borschiver, S. Bibliometria: uma ferramenta estatística para a gestão da informação e do conhecimento, em sistemas de informação e do conhecimento, em sistemas de informação, de comunicação e de avaliação científica e tecnológica. In: Encontro Nacional de Ciência da Informação, 2005, Salvador. Anais... Salvador: ICI/ UFBA, 2005. v.6, p.1-18.

Gomes, M. H. S. C.; Oliveira, E. C. O.; Bresciani, L. P.; Pereira, R. S. Política Nacional de Resíduos Sólidos: perspectivas de cumprimento da Lei 12.305/2010 nos municípios brasileiros, municípios paulistas e municípios da região do ABC. Revista de Administração da UFSM, 7, Edição Especial, 93-110, 2014. Disponível em: <http:// cascavel.ufsm.br/revistas/ojs-2.2.2/index.php/reaufsm/ article/view/13026/pdf>

Guardabassio, E. V. Gestão pública de resíduos sólidos urbanos na região do grande ABC. 2014. 249 f. Dissertação (Mestrado em Administração) - Universidade Municipal de São Caetano do Sul, São Caetano do Sul, 2014.

Huckle, J. Realizing sustainability in changing times. In: Huckle, J.; Sterling, S. (Eds.). Education for Sustainability. Sterling, VA: Earthscan, 2014.

Leite Filho, G. A. Padrões de Produtividade de Autores em Periódicos e Congressos na Área de Contabilidade no Brasil: um Estudo Bibliométrico. RAC-Revista de Administração Contemporânea, 2008. Disponível em: $<$ http://www.scielo. br/pdf/rac/v12n2/a11v12n2>

McDougall, F.; White, P. R.; Frank, M.; Hindle, P. Integrated solid waste management: a lifecycle inventory. Blackwell Science, 2001.
Mebratu, D. Sustainability and sustainable development: historical and conceptual review. Environmental Impact Assessment Review, 18, 493-520, 1998.

Nascimento, L. F.; Lemos, A. D. C.; Mello, M. C. A. Gestão socioambiental estratégica. Porto Alegre: Bookman, 2008.

OECD - Organization for Economic Co-operation and Development. Sustainable development: critical issues. Paris: OECD Publications, 2001.

Oliveira, M. C. Análise dos periódicos brasileiros de contabilidade. Revista Contabilidade \& Finanças, 29, 68-86, 2002.

ONU - Organização das Nações Unidas. Acordo de Paris - Convenção quadro sobre mudança de clima. 2015. Disponível em: $<$ https://nacoesunidas.org/wp-content/uploads/2016/04/Acordo-de-Paris.pdf $>$. Acesso em: jun. 2017.

Pearce, D.; Turner, R. Economía de los recursos naturales $y$ del medio ambiente. Madrid: Celeste Ediciones, 1995.

Pinto, C. M. Metanálise qualitativa como abordagem metodológica para pesquisas em letras. Atos de pesquisa em educação, 8(3), 1033-1048, 2013.

Sachs, I. Estratégias de transição para o século XXI - desenvolvimento e meio-ambiente. São Paulo: Studio Nobel/ FUNDAP, 1993.

Sachs, I. Desenvolvimento: includente, sustentável e sustentado. Rio de Janeiro: Garamond, 2008.

SEMEAD - Seminários em Administração - FEA-USP. Anais do XIV SEMEAD. São Paulo, 2011.

SEMEAD - Seminários em Administração - FEA-USP. Anais do XV SEMEAD. São Paulo, 2012.

SEMEAD - Seminários em Administração - FEA-USP. Anais do XVI SEMEAD. São Paulo, 2013.

SEMEAD - Seminários em Administração - FEA-USP. Anais do XVII SEMEAD. São Paulo, 2014.

SEMEAD - Seminários em Administração - FEA-USP. Anais do XVIII SEMEAD. São Paulo, 2015.

SEMEAD - Seminários em Administração - FEA-USP. Anais do XVIII SEMEAD. São Paulo, 2016. 
Silva, A. C. B.; Oliveira, E. C.; Ribeiro Filho, J. F. Revista contabilidade e finanças - USP: uma comparação entre os períodos 1989/2001 e 2001/2004. Revista de Contabilidade \& Finanças, 39, 20-32, 2005.

Silva L. C.; Roza B. C.; Rathmann R. Gestão de resíduos sólidos urbanos na cidade do Porto (Portugal): um exemplo de prática sustentável? RGSA - Revista de Gestão Social e Ambiental, 6(2), 60-78, 2012.

SIMPOI - Simpósio de Administração da Produção, Logística e Operações Internacionais. Anais do XIV SIMPOI. São Paulo, 2011.

SIMPOI - Simpósio de Administração da Produção, Logística e Operações Internacionais. Anais do XV SIMPOI. São Paulo, 2012.
SIMPOI - Simpósio de Administração da Produção, Logística e Operações Internacionais. Anais do XVI SIMPOI. São Paulo, 2013.

SIMPOI - Simpósio de Administração da Produção, Logística e Operações Internacionais. Anais do XVII SIMPOI. São Paulo, 2014.

SIMPOI - Simpósio de Administração da Produção, Logística e Operações Internacionais. Anais do XVIII SIMPOI. São Paulo, 2015.

SIMPOI - Simpósio de Administração da Produção, Logística e Operações Internacionais. Anais do XVIII SIMPOI. São Paulo, 2016.

Waldman, M. Lixo: cenários e desafios - abordagens básicas para entender os resíduos sólidos. São Paulo: Cortez, 2010. 